\title{
Las relaciones entre la masonería italiana y la masonería cubana
}

\section{Relations between Italian Freemasonry and $\mathrm{Cu}-$ ban Freemasonry}

\author{
Emanuela Locci \\ Universidad de Cagliari, Italia \\ loccimanuela@tiscali.it
}

Recepción: 20 de diciembre de 2019/Aceptación: 14 de abril de 2020

doi:https://doi.org/10.15517/rehmlac.v12i1-2.39538

\section{Palabras clave}

Masonería cubana; Gran Oriente de Italia; Ettore Ferrari.

\section{Keywords}

Cuban Freemasonry; Grand Orient of Italy; Ettore Ferrari.

\section{Resumen}

El Gran Oriente de Italia (GOI) ha mantenido y mantiene relaciones con algunas de las obediencias más importantes del mundo. En este caso, se investigó las relaciones entre el Gran Oriente de Italia y la Gran Logia de Cuba, mediante el estudio y el análisis de las fuentes que se encuentran en el Archivo Histórico del Gran Oriente de Italia y, para el período más reciente, en el Gran Secretariado. El archivo histórico del GOI conserva algunos documentos y números de las Revista de la Masonería Italiana que atestiguan las relaciones entre las dos Obediencias desde finales del siglo XIX.

\section{Abstract}

The present paper shows the relations Italian Freemasonry - the Grand Orient of Italy (GOI) - has been keeping with some of the most relevant Obediences in the world. Between G.O.I. and the Grand Lodge of Cuba. the research was carried out mostly through the analysis of documents and periodicals in the Historical Archive of the Grand Orient of Italy and, for more recent information, in the Grand Secretariat. The GOI historical archive preserves some documents and numbers from Rivista della Massoneria Italiana that witness the relations between the two Obediences since the end of the 19th century. 
La investigación se centra en las relaciones, pasadas y actuales, entre el Gran Oriente de Italia y la Gran Logia de Cuba. El vínculo entre las dos obediencias remonta a finales del siglo XIX y continúa hasta nuestros días. Gracias al estudio de las fuentes, encontradas en el archivo del Gran Oriente de Italia, se puede ver de inmediato que las relaciones entre las dos obediencias siempre han sido muy intensas, una intensidad que se evidencia sobre todo por las noticias constantes procedentes de Cuba y que se encuentran en las publicaciones masónica italianas. Mediante estos informes es posible, por un lado, reconstruir la historia de la masonería cubana y, por el otro, entender la grandeza y el valor de la relación entre los masones italianos y los cubanos.

Las primeras referencias remontan a 1880 cuando se produjo la unión entre las Grandes Logias que se encontraban en Cuba desde muchísimos años atrás: la Gran Logia de Colón ${ }^{1}$ y la Gran Logia de la isla de Cuba². Otras noticias se referían más específicamente a las actividades masónicas relacionadas con el mundo profano. Se mencionan a menudo las actividades benéficas de la masonería en favor de los más débiles. Esta característica se realizó en concreto, por ejemplo, en 1883, cuando devolvió más de mil pesos de oro a favor del hospital de Cuba para comprar ropa para los pobres33. Otros ejemplos de filantropía masónica ${ }^{4}$ fueron la institución de un premio anual de doscientos pesos para los que habían cumplido un acto meritorio, fuese masón o no5 , y el centro de vacunación gratuita activo en todo el país, con el objetivo de debelar la viruela que en ese momento cobraba muchas víctimas entre la población ${ }^{6}$. En 1889 se daba noticia de que la logia Plus Ultra, con sede en la capital, había iniciado la institución de un "jardín de infancia” para la educación primaria y secundaria de los hijos de los masones? Los italianos esperaban que este ejemplo fuese seguido por otras logias en todo el mundo para que la masonería lograse otro objetivo: la difusión del conocimiento y la educación para todos ${ }^{8}$.

En el periodismo masónico de Italia, en particular en la Rivista della Massoneria Italiana, el órgano de información del GOI ${ }^{9}$, que fue ampliamente usada en la elaboración de este artículo, hay mucha información sobre la vida de la masonería cubana, sobre la fundación o

$1 \quad$ La Gran Logia de Colón fue fundada el 5 de diciembre 1859 en Santiago de Cuba. Su primer Gran Maestro fue Francisco de Griñán.

2 En esa ocasión se reunieron 28 logias bajo la jurisdicción de la Gran Logia de Colón y 18 de la Gran Logia de la isla de Cuba. "Notizie massoniche estere" Rivista della Masoneria Italiana 16 (1880): 250.

3 “Cuba", Rivista della massoneria Italiana 15-16 (1883): 244.

4 Con el tiempo hubo otras iniciativas como la construcción en 1890 de una escuela para niñas: este proyecto fue el primero de una serie, para lograr uno de los objetivos de la masonería, la educación gratuita. "Notizie massoniche estere". Rivista della massoneria Italiana 18-19-20 (1890): 302.

5 "Cuba", Rivista della massoneria Italiana 17-18 (1884): 141.

6 "America", Rivista della massoneria Italiana 14-15 (1891): 227.

7 “Giardino d'infanzia massonico”, Rivista della massoneria Italiana 4-5 (1889): 65.

8 "Noizie massoniche estere", Rivista della massoneria Italiana 4-5 (1889): 65.

9 El GOI que es la más grande y antigua Obediencia italiana fue fundada en 1805. Su primer gran maestro fue el virrey de Italia Eugenio de Beauharnais y como Gran canciller el príncipe Gioacchino Murat. La primera asamblea constituyente del GOI fue organizada el 20 de diciembre de 1860. Los primeros problemas a afrontar eran los de la eccesiva fragmentación de la masonería italiana: diversas logias en el territorio italiano eran, de hecho, todavía ligadas a la obediencia del Gran Oriente de Francia. El Gran Oriente conoció un periodo de gran vitalidad entre finales del siglo XIX y el comienzo del XX, con las grandes maestrías de Adriano Lemmi, que potenció la institución favoreciendo el ingreso en las logias también en clases menos pudientes, y de Ernesto Nathan, que se volvió también sindico de Roma de 1907 a 1913, ambos dejaron una huella decisiva en la Obediencia. A Nathan siguió el escultor Ettore Ferrari, que guió la obediencia hasta la reelección de Nathan, pero ya se presentaban tiempos muy difíciles para la institución. Había subido al poder el fscismo y la masonería en 1925 fue prohibida por el Estado. Para profundizaren el tema del nacimiento y desarrollo del Gran Oriente de Italia, véase: Emanuela Locci (coord), History of the Grand Orient of Italy (Washington: Westphalia Press, 2019). 
la destrucción de las logias, sobre masones importantes y sobre las actividades de cada logia cubana $^{10}$. Por ejemplo, es de 1881 el anuncio de que las tres Grandes Logias Simbólicas que existían en Cuba, las tres con sede en La Habana, se habían fundido el 15 de noviembre de $1891^{11}$.

Un año más tarde se anunciaba la institución de la Logia Los Puritanos en Matanzas: con una doble ceremonia se inauguró la Logia y se decidieron los cargos $^{12}$. En el acto asistieron muchos hermanos de las logias existentes que ya estaban operando en territorio cubano. Mientras tanto, en la capital, La Habana, había 24 logias, y otras 22 trabajaban en el resto de la isla. Estos números prueban el desarrollo de la institución en el país, y el hecho de que la noticia se encontrara en la revista masónica más importante ${ }^{13}$, muestra que la masonería italiana era muy atenta a los acontecimientos que afectaban a la masonería cubana. También llegaban noticias, como la de dos masones pertenecientes a la logia Amerigo Vespucci, que fueron expulsados de la masonería, por haberse batido en duelo después de una violenta discusión ${ }^{14}$.

De esos mismos años son las noticias relativas a fiestas masónicas, como los solsticios. Es de 1893 la noticia de que algunas logias ${ }^{15}$ se reúnen para celebrar el solsticio de verano: la participación de los hermanos y de sus mujeres fue tan significativa que algunos huéspedes se vieron obligados a tomar lugar en el "Salón de los pasos perdidos"”.

La masonería se preocupa también por la instrucción masónica de sus iniciados y, por eso, se publicó una guía masónica que pretendía ser un manual para los Maestros y los Secretarios de las logias para que accedieran a todas las noticias relacionadas con las actividades masónicas en $\mathrm{Cuba}^{17}$.

Como ya hemos dicho, las primeras relaciones entre las dos Logias masónicas remontan a los finales del siglo XIX y, aunque no oficialmente, la masonería italiana fue muy cercana a la cubana también durante la Guerra de Independencia de España ${ }^{18}$. Como sabemos, Cuba era una colonia española, pero a finales del siglo XIX se había creado un movimiento nacionalista que no quería someterse al poder español. Fueron diversas las ocasiones en que los cubanos buscaron obtener la independencia. Entre 1868 y 1878 se llevó a cabo la primera guerra de independencia que, sin embargo, no trajo los resultados esperados para los cubanos. Luego, siguió la pequeña guerra (1879-1880) que se concretó en insurrecciones populares armadas que fueron reprimidas con sangre. Precisamente en la pequeña guerra murió en combate el poeta y patriota intelectual José Martí, considerado el padre de la patria cubana y personaje muy reconocido ${ }^{19}$ en el ambi-

\footnotetext{
10 "Notizie massoniche estere", Rivista della massoneria Italiana 12-13 (1894): 203.

11 "Notizie massoniche estere", Rivista della massoneria Italiana 8-9 (1892): 140.

12 "Notizie massoniche estere", Rivista della massoneria Italiana 18-20 (1892): 289.

"Notizie massoniche estere", Rivista della massoneria Italiana 4-5-6 (1892): 87.

"America", Rivista della massoneria Italiana 12-13 (1892): 202.

Se trataba de las logias Nuovo Mondo no. 5, Quisquella no. 15, Restauración no. 11, Perfecta Armonía no. 4, Hijos de la Fè no. 19. “America”, Rivista della massoneria Italiana 14-15-16-17 (1893): 250.

"Isola di Cuba", Rivista della massoneria Italiana 20-21 (1883): 320.

Con el Tratado de Paris en diciembre de 1898 España renunciaba a Cuba, después de cuatrocientos años de dominación. José Martí (La Habana, 1853 - Boca de Dos Ríos 1895) fue un patriota y escritor cubano. Su carrera como escritora comenzó muy temprano, cuando a los dieciséis años, fundó el periódico "La Patria Libre", en el que publicó el poema patriótico Abdala. En 1869 por sus actividades subversivas que fue detenido y condenado a seis años de prisión, dos años después su sentencia fue conmutada en la obligación de mudarse a España, donde continuó sus estudios de derecho. Después de estos dos años se mudó a México y Guatemala. De vuelta a Cuba en 1879, fue deportado de nuevo a España por sus actividades de propaganda en favor de la independencia de la isla. Llegado a Nueva York, fue correspondiente de varios periódicos latinoamericanos, con cargos
} 
ente masónico. Cuba logró obtener la independencia solo en 1898: su liberación de España se debió, en gran parte, a la intervención de los Estados Unidos que, al ver en peligro sus propios intereses en la isla, intervinieron al lado de los revolucionarios. El hundimiento de la acorazada americana Maine fue el casus belli que hizo que se desatara la guerra hispano-americana ${ }^{20}$. España fue rápidamente vencida en varios frentes y Cuba obtuvo la tan suspirada independencia ${ }^{21}$ aunque después debían sufrir la influencia norteamericana. El control americano de la isla se extendió desde 1899 hasta 1902, año de la fundación de la república.

Durante el periodo de la guerra de independencia, la masonería fue sorprendida con un decreto del capitán general Emilio Callejas, el 4 de abril de $1895^{22}$. Solo después de la guerra, la institución masónica volvió a estar activa y a reorganizarse y a cambiar su orientación cuando masones ilustres como Aurelio Miranda Álvarez, Fernando Figueredo Socarras y otros, volvieron a Cuba y reorganizaron la masonería junto a los Hermanos que quedaron en la patria y contribuyeron a dar a la institución una orientación patriótica que tenía como pilar la defensa de los principios republicanos. Todo eso bajo los auspicios de la masonería de los Estados Unidos ${ }^{23}$.

En Italia, la lucha cubana por la independencia había despertado un interés real, sobre todo en los círculos democráticos, que siempre se habían mostrado sensibles a las necesidades de los pueblos en busca de la libertad y de independencia. Una de las personas clave en la campaña de Italia por Cuba fue Francesco Federico Falco ${ }^{24}$. Gracias a la acción de Falco y de otros 11 miembros, todos figuras políticas prominentes -como Giovanni Bovio, Antonio Fratti, Salvatore Barzilai, Federico Gattorno, Federico Zuccari, Emilio Nissolino, Ferruccio Tolomei, Ettore Ferrari, Felice Albani y su esposa Alina ${ }^{25}$ - se formó en Roma, el 4 de abril de 1896, el Comité Central de Italia por la Libertad de Cuba ${ }^{26}$.

Se debe subrayar la presencia de masones en el comité, en particular de miembros prominentes del Gran Oriente de Italia (GOI), o sea Bovio, Barzilai, Gattorno, Zuccari y Ferrari ${ }^{27}$.

En este gran movimiento de personas y acontecimientos, parece muy importante para

de representante diplomático de Argentina, Uruguay y Paraguay; publicó Ismaelillo (1882) y Versos sencillos (1891). En 1892 creó el Partido de la Revolución Cubana y su órgano de prensa, Patria. Regresó a Cuba en 1895 y murió durante la insurrección contra España. Se considera uno de los héroes de la independencia de Cuba. Su figura es también muy popular dentro de la masonería, de la que formaba parte de la edad de dieciocho años. Para más información sobre este aspecto ver http://www. granlogiacuba.org/martimason (3 junio 2017).

20 Para una profundización en el tema ver Leslie Bethell (ed.), Cuba: A short History (Cambridge: Cambridge University Press, 1993).

21 Giovanni Sabattuci, Vittorio Vidotto, Storia contemporanea, l'Ottocento (Roma: Laterza, 2003), 276.

22 Eduardo Torres-Cuevas, Historia de la masoneria cubana, seis ensayons (La Habana: Imagen Contemporanea, 2013$), 106$.

23 Dominique Soucy, Masonería y nación: redes masónicas y políticas en la construcción identitaria cubana (1811-1902) (Canarias: Ediciones Idea, 2006), 352.

24 Francesco Federico Falco nació en Penne en 1866, en una familia de tradiciones renacientes. Se graduó en medicina en Bologna y se dedicó desde el principio a otra pasión: la actividad editorial política, con la dirección del papel radicales «La scintilla».

25 Adele Albani Tondi (1863-1939) nace en una familia cercana a los ideales mazzinianos y se casó con Felice Albani, con quien compartió la responsabilidad política y social. Siemrpe estuvo muy empeñada en la lucha por los derechos femeninos y en 1907 fundó el diario "Fede Nuova. Diario Femenino de propaganda mazziniana, político, social y religioso". Ver S. Bortoloni, Donne di fronte alla guerra: pace, diritti e democrazia (Bari: Laterza, 2017).

26 Archivo Histórico del Gran Oriente de Italia, de ahí en adelante. (ASGOI), Relazione del Comitato Centrale Italiano, la sua opera come si svolse e come termina, 2.

27 Marco Novarino, "Masonería Italiana y la Independencia de Cuba", en Masoneria española y America, coord. José Antonio Ferrer Benimeli (Zaragoza: CEHME, 1993), 1042. 
las relaciones con Cuba y con su masonería, la figura de Ettore Ferrari, Masón destacado y, en aquellos años, Gran Secretario del Gran Oriente de Italia. Se esforzó en todas las maneras por la organización del comité y en 1896, junto a Falco, publicó el documento "La lucha de Cuba y la solidaridad italiana” ${ }^{28}$. Los italianos se movilizaron sobre todo después de la muerte -en misteriosas circunstancias- de Antonio Maceo y Grajales (1845-1896) ${ }^{29}$, considerado el "Garibaldi” cubano. Antonio Maceo es considerado uno de los protagonistas de la independencia cubana, gracias a sus cualidades como estratega militar que le otorgaron buena fama durante la larga lucha por la independencia de Cuba en la que participó entre 1868 y 1898. Su fama sobrepasó los confines cubanos y llegó hasta los Estados Unidos, sobre todo en referencia a sus victorias militares y a su origen mestizo ${ }^{30}$. Incluso, cuando murió en batalla, el 6 de diciembre de 1896 , los americanos realizaron un reporte que subrayaba sus capacidades ${ }^{31}$. También los italianos lo recordaban a menudo como en el caso de la publicación conmemorativa del Comité Central italiano para Cuba, en el panfleto de 1905.

El trabajo del comité produjo la creación de un círculo dedicado a Maceo y dirigido por Emilio Nissolino ${ }^{32}$. Este círculo -según las fuentes de la prefectura- en 1898 logró los 50 miembros $^{33}$. Las reuniones del comité se tenían en casa del doctor Falco o cerca de la sede de la Asociación Garibaldina. Al interior del comité convivían diversas almas según el origen de sus exponentes, había parlamentarios, masones, exponentes de la cámara de trabajo, prensa, cuerpo de voluntarios garibaldinos, asociación Italia irredenta, consejo provincial y comunal de Roma, mundo del arte y un grupo de mujeres del Comité de las Mujeres Italianas. Muy presentes estaban tanto el Partido Republicano como el Radical, que en Roma dieron vida a una serie de actividades propagandísticas en favor de la causa cubana ${ }^{34}$. Algunos jóvenes italianos convencidos de poder dar su propia contribución a la causa cubana, también gracias a la fuerte propaganda llevada a cabo por el comité, partieron a la vuelta de Cuba. En 1898 también partió el doctor Falco, a pesar de muchas dificultades, tanto logísticas como económicas ${ }^{35}$.

Los acontecimientos de Cuba afectaron directamente a los vértices de la masonería italiana a partir de 1897 , junto a los hechos de Candia ${ }^{36}$. Aunque el movimiento de solidaridad de Cuba fue un éxito popular y, de alguna manera, también mediático, fue pronto muy evidente que el comité -también a causa de las condiciones económicas generales en Italia, con motivo

28 Maura Tesei, "Ferrari e il comitato pro-Cuba", in Il progetto liberal-democratico di Ettore Ferrari. Un percorso tra politica e arte, ed. Anna Maria Isastia (Milano: FrancoAngeli, 1997), 214.

29 Para un análisis completo ver Jorge Renato Ibarra Guitart (coord.), Maceo en el Tiempo. Acción, pensamiento y entorno histórico (La Habana: Editorial de Ciencias Sociales, 2015); Patricia Weiss Fagen, “Antonio Maceo: Heroes, History, and Historiography", Latin American Research Review 11, no. 3 (1976): 69-93.

30 Antonio Maceo era hijo de padre venezolano y madre afrocubana, Mariana Grajales Cuello (1815-1893) es un ícono cubano de la lucha de las mujeres y de la lucha por una Cuba independiente libre de la esclavitud, http://www.sierramaestra.cu/index.php/ santiago-de-cuba/historia/28570-mariana-grajales-coello-simbolo-y-ejemplo-para-la-mujer-cubana Philip S. Foner, “A tribute to Antonio Maceo", The Journal of Negro History 1 (1970): 66. Para profundizar la figura de Maceo véase Torres-Cuevas, Antonio Maceo.las Ideas Que Sostienen El Arma (La Habana: ediciones imagen contemporanea, 2012). Fernado Ortiz Fernández, Las simpatías de Italia, documentos (Marsella, 1905), 24.

Francesco Tamburini, "L'indipendenza di Cuba nella coscienza dell'estrema sinistra italiana (1895-1898)", Spagna Contemporanea 7 (1995): 51.

Tamburini, "L'indipendenza di Cuba", 42.

Ortiz Fernández, Las simpatias de Italia, 25.

La rebelión de Candia tuvo lugar entre 1897 y 1898: el pueblo griego se levantó contra el dominio del Imperio Otomano, dueño de la isla desde 1669. Muchos italianos, entre ellos un gran grupo de partidarios bajo el mando de Ricciotti Garibaldi se fue a luchar junto a los griegos. Ver Emanuela Locci, "La solidarietà tra popoli e i garibaldini. Le spedizioni in terra ottomana", en Solidarietà antiche e moderne. Un percorso storico, coord. Pierpaolo Merlin (Carocci: Roma, 2017), 100-114. 
de las campañas de África- no podía apoyar económicamente a los revolucionarios, ni siquiera organizar cualquier envío de voluntarios. Se conformó una lista de voluntarios que, por fin, nunca partieron, mientras que otros -bajo el mando del coronel Gustavo Martinotti- se pusieron a disposición de la delegación cubana con residencia en Nueva York ${ }^{37}$. La historia de Martinotti es muy particular: veterano del levantamiento de Candia, el 7 de mayo de 1898 se embarcó, junto a otros 40 hombres, en un piróscafo Lloyd con destino a Nueva York. Una vez llegados a Estados Unidos, recibieron garantías por parte de los estadounidenses, y también por parte de los cubanos, que aseguraron que habrían podido participar en el combate. Pero así no fue y tres meses más tarde volvieron a Italia $^{38}$.

Según algunos escritores antimasónicos ${ }^{39}$, la masonería de Palazzo Giustiniani intervino directamente con el gobierno de Madrid para defender la causa de Cuba, pero de este asunto no hay pruebas documentales. Por eso, sigue siendo solamente una tesis encantadora y atractiva.

La masonería cubana, después de la guerra de independencia y la posterior fundación de la república, empezó una nueva fase de su existencia, que la llevará a jugar un papel muy importante en la construcción de la nueva identidad nacional ${ }^{+0}$. El vínculo con Italia se mantuvo también con el nacimiento de la república (20 de mayo de 1902) y, tres años después, en 1905, el Comité Italiano vuelve a reunirse para recordar los acontecimientos de la Guerra de Independencia de Cuba y sus protagonistas ${ }^{41}$.

Con el pasar de los decenios, la relación entre las dos obediencias no fue menor, aunque, lamentablemente, no hay documentos que puedan probarlo, porque se perdieron durante el periodo fascista.

Los acontecimientos históricos se suceden rápidamente también en Italia y con la llegada al poder de los fascistas llegan tiempos muy difíciles para la masonería italiana, que se ve obligada a parar su actividad ${ }^{42}$ y, por lo tanto, también sus relaciones con la masonería cubana. También Cuba estaba atravesando un periodo más bien turbulento, en 1924 fue electo presidente Gerardo Machado y Morales (1871-1939), que dirigió una serie de reformas y la construcción de infraestructura, pero la situación económica cubana estaba fuertemente ligada a la de Estados Unidos que en 1929 afrontó una crisis muy fuerte ${ }^{43}$. El presidente que rápidamente se hizo popular en 1933 fue exiliado y sustituido por Carlos Manuel Céspedes y Quesada (18711939). Después de un mes, una revuelta militar encabezada por Fulgencio Batista, salió de Céspedes. Un comité ejecutivo de cinco miembros comandó a un gobierno provisional y Ramón Grau San Martín fue entonces nominado presidente temporal. Grau dimitió en 1934, dejando espacio a Batista, que dominó la política cubana por los siguientes 25 años.

Ortiz Fernández, Las simpatías de Italia, 41.

Tamburini, "L'indipendenza di Cuba", 77.

Mauricio Luis Villalba Muñoz, La gran traición (Barcelona: Imprenta á cargo de Miguel Borrás, 1899).

Véase el sitio web de la Gran Logia de Cuba: http://www.granlogiacuba.org/masoneria-republica

Comitato Centrale Italiano, Italia per Cuba nel III anniversario della proclamazione della repubblica cubana (Roma: CCI, 1905), 1-16.

42 Fulvio Conti, Storia della massoneria italiana. Dal Risorgimento al fascismo (Milano: Il mulino, 2006).

43 Ver Clifford L. Staten, The History of Cuba (New York: Palgrave, 2003), 56-70. 
En cuanto al mundo masónico, era una situación transitoria, porque con la caída del régimen, la masonería italiana, constreñida desde 1925 a operar en el exilio ${ }^{44}$, se reorganizó. Esta reorganización también se produjo por medio de recíprocos reconocimientos que era necesario confirmar después de la interrupción del período fascista. En cuanto a las relaciones entre Italia y Cuba, en el momento del "despertar" de la masonería italiana, volvieron a empezar los regulares contactos con los hermanos cubanos, con intercambio de noticias y correspondencias.

Desde 1947 comenzó el largo proceso para la reanudación formal de las relaciones y el reconocimiento mutuo ${ }^{45}$. Guido $\mathrm{Laj}^{46}$ anunció su intención de presentar al Consejo Supremo del Rito Escocés de Cuba su solicitud de reconocimiento y de intercambio de $\operatorname{amistad}^{47}$. Por parte de Cuba, Francesco Segré, importante miembro de la Gran Logia, fue a Italia para recoger informaciones sobre la situación real de la masonería italiana. El Gran Maestro Laj, que se reunió con él en 1947, dio disposiciones para garantizar que al emisario cubano se le otorgara toda la documentación necesaria con el fin de proceder al reconocimiento mutuo ${ }^{48}$.

A pesar de ese encuentro, que no tuvo gran éxito y no hubo respuesta positiva por parte de Cuba, el año siguiente los masones italianos renovaron la solicitud de reconocimiento ${ }^{49}$.

Las negociaciones continúan durante mucho tiempo. En 1951 Publio Cortini ${ }^{50}$, en ese momento Gran Tesorero en la Junta Laj, escribe una carta a José F. Castellanos, que era el Gran Secretario de la Gran Logia de Cuba, pidiendo la reanudación de las relaciones fraternas y de amistad entre las dos Obediencias, y el nombramiento y el intercambio de los Grandes Representantes. Cortini aclaró en la carta que el Gran Oriente de Italia ya había restablecido relaciones con 34 Grandes Logias de Estados Unidos de América, con siete Grandes Logias de Brasil y con diez de México y de muchos otros países, de los que hace una lista muy detallada ${ }^{5}$.

El 10 de marzo de 1952, el hermano José F. Castellanos informa a Cortini ${ }^{52}$ de que la cuestión italiana se incluía en el orden del día de la sesión anual de la Gran Logia. Después de un año, el 21 de mayo de 1953, llega la carta oficial que anunciaba el reconocimiento efectivo de la Co-

44 Para más información ver Santi Fedele, La Massoneria italiana nell'esilio e nella clandestinità (1927-1939) (Milano: FrancoAngeli, 2005).

45 ASGOI, Lettera di Guido Francocci (Gran segretario), Roma, 4 octubre 1947, Grandi logge estere, Cuba, carta $14,1$.

46 Guido Laj, nació en Messina el 16 de abril de 1880, fue doctor en leyes, político y servidor público. Convencido antifascista, tras el fascismo, fue alcalde de Roma durante dos años. Se inició en la masonería en 1906 y después de la guerra se reanudó a la actividad de la Logia Masónica Cola di Rienzo en Roma y entre 1943 y 1945 formó parte del comité de maestría del Gran Oriente de Italia, junto con Umberto Cipollone y Gaetano Varcasia. El 18 de septiembre de 1945 fue elegido Gran Maestro, el primero después de la dictadura fascista, y permaneció en el cargo hasta el 5 de noviembre de 1948. Guido Laj se considera uno de los principales arquitectos de la reconstrucción de la masonería italiana después de la Segunda Guerra Mundial. Para más información ver Anna Maria Isastia, L'eredità di Nathan. Guido Laj (1880-1948) prosindaco di Roma e Gran Maestro (Roma: Carocci, 2006); Vittorio Gnocchini, L'Italia dei liberi muratori: brevi biografie di massoni famosi (Roma: Mimesis, 2005), $161-162$.

47 ASGOI, Messaggio manoscritto e sottoscritto da Guido Laj, Roma, obras 1947, Grandi logge estere, Cuba, carta 14 , 3.

48 ASGOI, lettera di Francesco Segrè, a Guido Laj, 24 febbraio 1948, Grandi logge estere, Cuba, carta 14, 1.

49 ASGOI, Grandi logge estere, Cuba, carta 14, 2.

50 Publio Cortini nació en Roma en 1895, industrial, fue Presidente de la sociedad "Mater", la industria más importante de la época. Su carrera comenzó en 1919 en la logia de Rienzi en Roma. Se convirtió en Maestro en 1921. Durante la maestranza Laj fue elegido Gran Tesorero, y en 1953 se convirtió en Gran Maestro. Su gran maestría se recuerda por su obra de reinserción Masonería Italiana en la comunidad internacional. Para más información sobre esta importante figura de la posguerra: Gnocchini, L'Italia dei liberi muratori: brevi biografie di massoni famosi, 84-85.

51 ASGOI, lettera Publio Cortini, capo delle relazioni estere, Roma, 4 octubre 1947, Grandi Logge Estere, Cuba, carta 14, 5.

52 Por supuesto, el decreto se hizo en una fecha posterior a la decisión ya tomada en la sesión anual de la Gran Logia a principios de mayo. 
munión italiana, indicada por el decreto de reconocimiento no. 188 del 10 de junio de $1953^{53}$. A partir de ese momento, empiezan de nuevo las relaciones oficiales entre las dos Obediencias. Cortini, en respuesta a la carta del 21 de mayo de 1953, escribe a Castellanos alegrándose por el reconocimiento y dando la bienvenida a la propuesta cubana de nombrar al hermano Amedeo Pacifico Bevilagua ${ }^{54}$ como Garante de la amistad $^{55}$. El representante de la Gran Logia de Cuba para el Gran Oriente de Italia era Carlo Speranza, como demuestra la carta de Cortini a Castellanos del 13 de septiembre de 1953, conservada en los archivos del Gran Oriente de Italia.

En aquel momento, el Gran Maestro de la masonería cubana era Carlos Manuel Piñeiro del Cueto que a través de su Gran Secretaría comenzó a enviar al Gran Oriente de Italia una serie de documentos que volvían a proponer la vida de la Gran Logia de Cuba. Es evidente, por esta correspondencia, la voluntad de mantener relaciones fuertes y duraderas con el Gran Oriente de Italia, construyendo una suerte de cotidianeidad en las noticias.

Llegaban a Roma noticias sobre las elecciones, los encargos, las renuncias, las renovaciones y cualquier otra información que se consideraba necesaria. El Gran Oriente de Italia hizo lo mismo, como se suele hacer entre Obediencias que se reconocen mutuamente.

Otro indicador de las relaciones entre las dos Obediencias es el viaje a Cuba de Publio Cortini -que mientras tanto había sido elegido Gran Maestro del Gran Oriente de Italia- entre finales de 1955 y principios de $1956^{56}$.

A lo largo de este período, es decir de 1953, año en el que se reanudaron las relaciones oficiales, hasta 1959, no existe en la documentación masónica ninguna referencia a la revolución cubana de Fidel Castro contra la dictadura de Fulgencio Batista, revolución que tuvo lugar entre 1953 y 1959. A partir de 1960 hay los primeros síntomas de un malestar dentro de la institución. El Gran Maestro Manuel Céspedes Mora escribió al equipo italiano para informarle del hecho de que algunos hermanos, entre ellos el ex-Gran Maestro Juan José Tarajano, abandonaban la isla para mudarse a Miami ${ }^{57}$, porque pensaban que el gobierno de Cuba habría podido representar un peligro para ellos. Lo que se temía era una posible infiltración del gobierno en la masonería con el fin de absorberla. El Gran Maestro Céspedes Mora, sin embargo, es de una opinión completamente diferente e incita a los hermanos masones -que eran más o menos 30 mil- a continuar sus actividades latomisticas en absoluta tranquilidad ${ }^{58}$.

\footnotetext{
53 Amedeo Pacifico Bevilagua era un miembro de la logia Pi Y Margall. De origen italiano, residente en Cuba desde hace más de treinta años. Fue miembro de la Società Italiana antifascista, de la asociación democrática Italia-Cuba Giuseppe Garibaldi y presidente del Instituto Dante Alighieri. Durante su mandato se hicieron investigaciones sobre su persona por presuntos vínculos con el fascismo en Italia que fueron negados por la investigación misma, que de hecho demuestra la fuerte propensión de su lucha contra el fascismo. Amedeo Pacifico Bevilagua, murió en 1974. ASGOI, lettera di Publio Cortini a José Castellanos, Roma, 27 giugno 1953, Grandi logge estere, Cuba, carta 14,1.

54 ASGOI, lettera di Publio Cortini a José Castellanos, Roma, 27 giugno 1953, Grandi logge estere, Cuba, carta 14, 2.

55 ASGOI, biglietto di ringraziamento di Publio Cortini alla Grande Loggia di Cuba per l'accoglienza ricevuta, maggio 1956, Grandi logge estere, Cuba, carta 14, 1.

56 El ex gran maestro Tarajano fundó en los EE.UU. la Gran Logia de Cuba en el Exilio, logia que más tarde se reconoció en la Conferencia de Grandes Maestros de Washington.

57 ASGOI, circolare grande loggia di Cuba 42/43, Grandi logge estere, Cuba, carta 14, que incluye lo decretos n. 654-655, firmados por el gran maestro Manuel Cespedes Mora.

58 Felipe Santiago del Solar, Confederación Masónica Interamericana, CMI (Montevideo / Santiago de Chile: Confederación Masónica Interamericana, 2017).
} 
La masonería cubana proclama que la Gran Logia con sede en Cuba es la única organización masónica regular y, en efecto, fue reconocida en la quinta conferencia de la Confederación Masónica Interamericana ${ }^{59}$. La confederación nació con el objetivo de crear un organismo que regulara las relaciones entre las Obediencias, especialmente las presentes en el área del centro y Sudamérica. Uno de sus puntos fuertes era el respeto de las normas en la regularidad masónica, por lo tanto, ser reconocida a su interior tenía un valor masónico muy alto.

Después de estas primeras preocupaciones, que poco después se convirtieron en aseguramientos por parte de los vértices de la Gran Logia, no hay otras noticias relevantes. Pero la situación fue deteriorándose y, de hecho, la financiación y las iniciativas privadas de caridad se redujeron, debido a los profundos cambios que afectaron a la sociedad civil cubana. A esto hay que añadir el creciente número de personas que eligieron el camino del exilio, y el número de los jóvenes que se unían a la masonería iba menguando. Estos factores de crisis provocaron una situación de profunda consternación dentro de la institución. Los miembros efectivos pasaron de 34 mil en 1959, a poco menos de 20 mil en $1981^{60}$. Cuando, a principios de los años ochenta del siglo pasado, parecía que el destino de la masonería en tierra cubana estaba marcado, la institución fue capaz de revertir completamente la tendencia y convertirse en uno de los pilares de la sociedad cubana. Hoy en día, la Gran Logia de Cuba tiene poco más de 29 mil hermanos ${ }^{61}$, distribuidos en 320 logias que se encuentran en todo el territorio cubano ${ }^{62}$.

Las relaciones entre el GOI y la Gran Logia de Cuba fueron fuertes y floridas al final del siglo pasado y siguen siendo tan fuertes y floridas. A menudo hay intercambios de correspondencia y de visitas que refuerzan este vínculo histórico. Los cargos más altos de la masonería cubana participan todos los años, con una gran delegación, en la Gran Logia que se celebra en Rimini. Para sellar una relación decenal, en el 2012 durante el simposio internacional que se llevó a cabo en La Habana sobre el tema: "Masonería e Integración en la Sociedad Actual”, el informe de apertura fue confiado al ahora Gran Maestro del Gran Oriente de Italia, Gustavo Raffi.

En 2013, el espíritu de solidaridad y unión fraterna resonó durante las labores de la Gran Logia en un encuentro organizado a propósito para dar la bienvenida a la delegación de la Gran Logia de Cuba. El Gran Maestro de la Gran Logia de Cuba, Evaristo Rubén Gutiérrez Torres, reiteró la peculiaridad de la experiencia libremasónica cubana, de ser una auténtica masonería de pueblo, profundamente enraizada en la sociedad y anclada a la historia del propio país. Además, ha querido subrayar la gran relación de fraterna amistad con la masonería del GOI, relación que viene de lejos en cuanto a que la masonería italiana estuvo en primera fila en la lucha por la independencia cubana. Los mismos conceptos fueron discutidos por el máximo exponente del Rito Escocés Antiguo y Aceptado, Lázaro Faustino Cuesta Valdés, que además agradeció al Gran Maestro del Gran Oriente de Italia por su trabajo para dar a conocer la situación de la masonería cubana, empeño que ha mejorado sensiblemente las relaciones in-

\footnotetext{
59 Consúltese el sitio web de la Gran Logia de Cuba: http://www.granlogiacuba.org/masoneria-revolucion

60 El dato es significativo si se considera la población total de once millones de habitantes.

61 Véase el sitio web del Gran Oriente de Italia: http://www.grandeoriente.it/la-gran-loggia-di-cuba-una-realta-sconosciuta-29-000-fratelli-per-320-logge-il-ruolo-strategico-della-massoneria-cubana-nel-mondo-massonico/

62 Revísese el sitio web del Gran Oriente de Italia: https://www.grandeoriente.it/italia-e-cuba-per-una-massoneria-di-popolo/
} 
ternacionales. El encuentro concluyó con el otorgamiento por parte de la Gran Logia de Cuba del certificado de miembro honorario a Gustavo Raffi, al Gran Representante en la masonería cubana, Fabio Zandri.

Es en este contexto que las relaciones con el Gran Oriente de Italia en estos últimos años se reforzaron y consolidaron con concretos gestos de solidaridad como el sostén al proyecto de digitalización de la Biblioteca Masónica de la Gran Logia de Cuba.

\section{Observaciones finales}

El estudio de las fuentes que se encuentran en el Archivo y en la Gran Secretaría del Gran Oriente de Italia muestran con claridad una imagen muy positiva de las relaciones entre los masones italianos y los cubanos. Esta relación comenzó durante la segunda mitad del siglo XIX, atravesó el siglo XX y las vicisitudes debidas al oscurantismo fascista. Incluso en relación con los eventos finales del siglo XIX de la independencia de Cuba, se debe tener en cuenta que los que se dedicaron pública y políticamente a la causa cubana, pertenecían a los círculos masónicos. Cabe decir, como muestra el análisis de las fuentes, que el vínculo entre las dos Obediencias nunca se ha interrumpido, desde los primeros contactos que se remontan al final del ochocientos hasta hoy: nunca ha habido crisis o ruptura de ese vínculo, un vínculo que se caracteriza por una cooperación y hermandad, la más profunda posible, con la única excepción de los años del fascismo. Un dato que se destaca y que es muy interesante con respecto a los estudios llevados a cabo con anterioridad sobre la masonería en el área mediterránea es

lo que demuestra que no hay logias italianas en Cuba. Esto indica que en la isla hay una sólida tradición masónica y, por lo tanto, las relaciones entre las logias son entre iguales. 
REHMLAC+, ISSN 2215-6097, vol. 12, nos. 1-2, julio 2020 / diciembre 2020

\section{Bibliografia}

Bethell, Leslie. Cuba: A short History. Cambridge: Cambridge University Press, 1993.

Comitato Centrale Italiano. Italia per Cuba nel III anniversario della proclamazione della repubblica cubana. Roma: CGI, 1905.

Conti, Fulvio. Storia della massoneria italiana. Dal Risorgimento al fascismo. Milano: Il mulino, 2006.

Fedele, Santi. La Massoneria italiana nell'esilio e nella clandestinità (1927-1939). Milano: FrancoAngeli, 2005.

Foner, Philip S. “A tribute to Antonio Maceo". The fournal of Negro History 1 (1970): 66.

Gnocchini, Vittorio. L'Italia dei liberi muratori: brevi biografie di massoni famosi. Roma: Mimesis, 2005.

Ibarra Guitart, Jorge Renato, coord. Maceo en el tiempo. Acción, pensamiento y entorno histórico. La Habana: Editorial de Ciencias Sociales, 2015.

Isastia, Anna Maria. L'eredità di Nathan. Guido Laj (1880-1948) prosindaco di Roma e Gran Maestro. Roma: Carocci. 2006.

Locci, Emanuela, coord. History of the Grand Orient of Italy. Washington: Westphalia Press, 2019.

Locci, Emanuela. “La solidarietà tra popoli e i garibaldini. Le spedizioni in terra ottomana”. En Solidarietà antiche e moderne. Un percorso storico. Coordinado por Pierpaolo Merlin. Carocci: Roma 2017.

Murphy, Warran H. "A History of Freemasonry in Cuba”. Walter Lodge of Research 4 (1974): 69-78.

Novarino, Marco. "Masonería Italiana y la Independencia de Cuba”. En Masoneria española y America. Coordinado por José Antonio Ferrer Benimeli. Zaragoza: 1993.

Ortiz Fernandez F. Las simpatías de Italia, documentos. Marsella, 1905.

Romeu, Jouge Luis. "Análisis de la visión de algunos europeos, sobre las masonerías autóctonas de Cuba y Puerto Rico, a finales del siglo XIX”, REHMLAC+ 10, no. 1 (mayo-noviembre, 2018): 89-107, https://revistas.ucr.ac.cr/index.php/rehmlac/article/view/32105/33059

Sabattuci Giovanni, Vidotto Vittorio. Storia contemporanea, l'Ottocento. Roma: Laterza, 2003.

Solar, Felipe Santiago del. Confederación Masónica Interamericana, CMI. Montevideo / Santiago de Chile: Confederación Masónica Interamericana, 2017. 
REHMLAC+, ISSN 2215-6097, vol. 12, nos. 1-2, julio 2020 / diciembre 2020

Soucy, Dominique. Masonería y nación: redes masónicas y políticas en la construcción identitaria cubana (1811-1902). Spain: Ediciones Idea, 2006.

Staten Clifford L. The History of Cuba. New York: Palgrave, 2003.

Tamburini, Francesco. "L'indipendenza di Cuba nella coscienza dell'estrema sinistra italiana (1895-1898)". Spagna Contemporanea 7 (1995): 39-80.

Tesei, Maura. "Ferrari e il comitato pro-Cuba". En Il progetto liberal-democratico di Ettore Ferrari. Un percorso tra politica e arte. Coordinado por Anna Maria Isastia. Milano: Franco Angeli, 1997.

Torres- Cuevas, Eduardo. Antonio Maceo. Las ideas que sostienen el Arma. La Habana: Imagen Contemporanea, 2012.

Torres-Cueva, Eduardo. Historia de la masonería cubana, seis ensayos. La Habana: Imagen Contemporanea, 2013.

Villalba Muñoz, Mauricio Luis. La gran traición. Barcelona: imprenta á cargo de Miguel Borrás, 1899.

Weiss Fagen Patricia, "Antonio Maceo: Heroes, History, and Historiography". Latin American Research Review 11, no. 3 (1976): 69-93. 